\title{
Modifications on Microporosity and Physical Properties of Cement Mortar Caused by Carbonation: Comparison of Experimental Methods
}

\author{
Son Tung Pham \\ Laboratory of Civil Engineering and Mechanical Engineering, Department of Civil Engineering, \\ National Institute of Applied Sciences, 35000 Rennes, France
}

Correspondence should be addressed to Son Tung Pham; spham@insa-rennes.fr

Received 20 May 2013; Revised 31 July 2013; Accepted 1 August 2013

Academic Editor: Yucel Birol

Copyright (C) 2013 Son Tung Pham. This is an open access article distributed under the Creative Commons Attribution License, which permits unrestricted use, distribution, and reproduction in any medium, provided the original work is properly cited.

\begin{abstract}
The influence of carbonation on the microstructure of normalised CEM II mortar was studied using nitrogen adsorption and porosity accessible to water. Samples were prepared and subjected to accelerated carbonation at $20^{\circ} \mathrm{C}, 65 \%$ relative humidity, and $20 \% \mathrm{CO}_{2}$ concentration. Conflicts in results were observed because while the pore size distributions calculated by BJH method from nitrogen adsorption provided evolution of the micro- and mesopores during carbonation, the porosity accessible to water showed changes in all three porous domains: macro-, meso- and micropores. Furthermore, the porous domains explored by water and nitrogen molecules are not the same because of the difference in the molecular sizes. These two techniques are therefore different and help to complementarily evaluate the effects of carbonation. We also examined the evolution of macrophysical properties such as the solid phase volume using helium pycnometry, gas permeability, thermal conductivity, thermal diffusivity, and longitudinal and transverse ultrasonic velocities. This is a multiscale study where results on microstructural changes can help to explain the evolution of macro physical properties.
\end{abstract}

\section{Introduction}

The carbonation is a natural aging process for all cement materials. It corresponds to the progressive transformation of principal constituents of cementitious matrix, the portlandite $\mathrm{Ca}(\mathrm{OH})_{2}$, and the calcium silicate hydrate $\mathrm{C}-\mathrm{S}-\mathrm{H}$ into calcite $\mathrm{CaCO}_{3}$, in contact with the carbon dioxide in the air and in the presence of water in the pores. This transformation is accompanied by a decrease in $\mathrm{pH}$. The principle reactions are

$$
\begin{gathered}
\mathrm{CO}_{2}+\mathrm{Ca}(\mathrm{OH})_{2}=\mathrm{CaCO}_{3}+\mathrm{H}_{2} \mathrm{O} \\
\mathrm{C}_{x} \mathrm{~S}_{y} \mathrm{H}_{z}+x \mathrm{H}_{2} \mathrm{CO}_{3}= \\
x \mathrm{CaCO}_{3}+y \mathrm{SiO}_{2} \cdot t \mathrm{H}_{2} \mathrm{O} \\
+(x-t+z) \mathrm{H}_{2} \mathrm{O}
\end{gathered}
$$

The progress of these carbonation reactions causes a change in the microstructure, which is highlighted by various parameters such as variations in porosity, specific surface area, and pore size distribution. These microstructural evolutions during carbonation lead obviously to changes in the macro physical properties such as the solid phase volume, the gas permeability, the thermal properties, and the ultrasonic velocities.

The reduction of $\mathrm{pH}$ induces the depassivation and corrosion of the steel rebar. The duration for $\mathrm{CO}_{2}$ to reach the rebar is often regarded as the service time of the reinforced concrete structure. The onset of the corrosion can be predicted by the assessment of durable indicators [1]. Among physical properties mentioned above, only the gas permeability is considered as a durable indicator; other physical properties still need more research to be taken into account in assessing the durability of structures in $\mathrm{CO}_{2}$ environment [1].

The coherence between the observations on micro- and macroscales is still discussed. While most authors have observed a decrease in the porosity accessible to water $[2,3]$, this result cannot explain the increase in the gas permeability observed by some authors $[2,4]$. Some investigators believe 
that the water molecule, because of its small radius of $0.1 \mathrm{~nm}$ [5], can penetrate not only into meso- and macropores (radius larger than $2 \mathrm{~nm}$ ) but also into nano- and micropores, while the nitrogen molecule cannot because of its larger radius of $0.21 \mathrm{~nm}$ [6]. Hence, the water porosity decreases after carbonation which means that the totality of pores decreases, but no specific information about the meso- and macropores, the porous domains which influence the gas permeability, can be drawn.

Although the mercury porosimetry method is suitable for meso- and macropores with radii of $2 \mathrm{~nm}$ to $60 \mu \mathrm{m}$, the high pressure which is needed to intrude the mercury into the pores might lead to the microdamage during the test and influence the results [7]. For this reason, we propose to investigate the evolution of the microstructure caused by the carbonation in a cementitious matrix using nitrogen adsorption, which is suitable for mesopores with radii of $2 \mathrm{~nm}$ to $32 \mathrm{~nm}$ [7]. We will report the change in the following areas: the cumulative pore volume, the BET specific surface area [8], and the pore size distribution. The observations on microstructural changes will help to discuss the evolutions of macro properties that we propose to measure, such as the solid phase volume, the gas permeability, the thermal conductivity, the thermal diffusivity, and the longitudinal and transverse ultrasonic velocities. Although the thermal conductivity is important for fire resistance and energy conservation, its evolution during carbonation of cement materials has never been studied. The porosity accessible to water and the carbonation depth will also be examined in order to draw complementary explanations for the changes in both micro- and macroscales.

\section{Materials and Methods}

2.1. Standardised Mortar CEM II. For this study, we used a normalised mortar prepared with Lafarge cement CEM II/BM (V-LL) 32.5 R and French standard sand certified in accordance with norm EN 196-1 and ISO 679:2009. The water/cement and sand/cement ratios were 0.5 and 3 , respectively. At the end of the mixing, the mortar was placed in cylindrical moulds $(\varnothing=40 \mathrm{~mm}, h=60 \mathrm{~mm})$. The samples were demoulded after 24 hours and then cured for 90 days in a humid chamber $\left(20^{\circ} \mathrm{C}, 100 \%\right.$ relative humidity).

The cement CEM II was chosen because of its availability. In developing countries, the CEM II is much more available than the CEM I. Moreover, Bier et al. [9] observed the creation of mesopores after carbonation of a mortar, which was not rich in portlandite and contained fly ash. The CEM II is poor in portlandite in comparison with CEM I, and therefore the CEM II was chosen for this study because we want to ensure significant changes not only in the micropores but also in the domains of meso- and macropores. The use of this non element cement in the study can be justified because the research provides information about the comparison of experimental methods applied to a specific mortar. Other researchers can later extend the study to their own mortar, in making their decision on which method to use to study the porosity of their mortar.
2.2. Carbonation Test. Before the carbonation test, the samples were dried at $105^{\circ} \mathrm{C}$ to a constant mass and then stored for 7 days at $20^{\circ} \mathrm{C}, 65 \%$ relative humidity for homogenisation in the internal humidity [10]. To implement the test, the samples were protected laterally using an adhesive tape and then subjected to axial diffusion of $\mathrm{CO}_{2}$ in an environmentally controlled chamber at $20^{\circ} \mathrm{C}, 65 \%$ relative humidity, and $20 \%$ $\mathrm{CO}_{2}$ concentration for a defined time. At the end of the test, the carbonated zone was determined using the classical phenolphthalein test. Every result obtained in this study is the average of at least 3 measures. The nitrogen adsorption and the porosity accessible to water were performed on noncarbonated and well-carbonated samples, while the measures of physical properties were performed on noncarbonated and partially carbonated samples.

2.3. Adsorption Desorption of Nitrogen. The nano- and microscopic scales consist of sheets of C-S-H. These sheets associated with packets are called grains and constitute a second level of the observation, which is the mesoscopic scale. To study this scale, we record the nitrogen adsorption desorption isotherms at $77 \mathrm{~K}$. The test is performed on grinding powders originated from the test samples. Nitrogen molecules are indeed adsorbed to the surface of grains corresponding to the packets of the sheets of $\mathrm{C}-\mathrm{S}-\mathrm{H}$ and to the packets of portlandite; however, they do not penetrate the space between the layers. The specific surface area analyser Micromeritics Gemini VII was used for this test. From adsorption desorption isotherms of nitrogen, the BET specific surface area [8] and the BJH pore size distribution [11] were calculated.

2.4. Gas Permeability. The test was performed in a helium permeameter under variable pressures: 1 bar, 2 bars, 3 bars, and 5 bars. For each pressure, we waited for the gas flow to become constant. The intrinsic permeability $K$ was then calculated in accordance with Cembureau method [12].

2.5. Thermal Properties. The thermal properties were performed at $20^{\circ} \mathrm{C}$ using a Hot Disk Thermal Constants Analyser TPS2500S. A plane Hot Disk sensor was fitted between two pieces of the sample-each one with a plane surface facing the sensor. By passing an electrical current, high enough to increase the temperature of the sensor between a fraction of a degree up to several degrees, and at the same time recording the resistance (temperature) increase as a function of time, the Hot Disk sensor was used both as a heat source and as a dynamic temperature sensor.

2.6. Helium Pycnometry. The actual volume was determined using helium pycnometry. This method consists of injecting a gas at a given pressure in a container of known internal volume containing the sample and then relaxing it in a second chamber of known volume. The measure of the new equilibrium pressure is used to calculate the actual volume of the sample using the ideal gas law. Micromeritics helium pycnometer AccuPyc II 1340 was used for this measurement. 


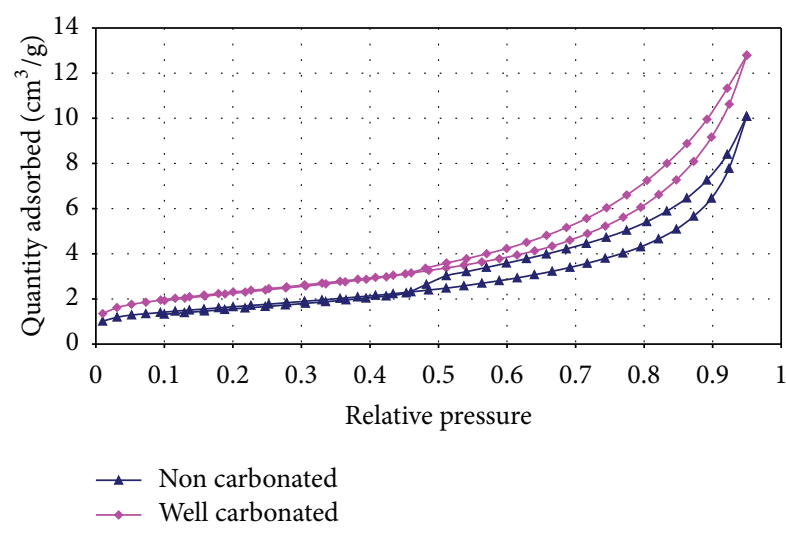

FIGURE 1: Nitrogen adsorption desorption on the powder sample.

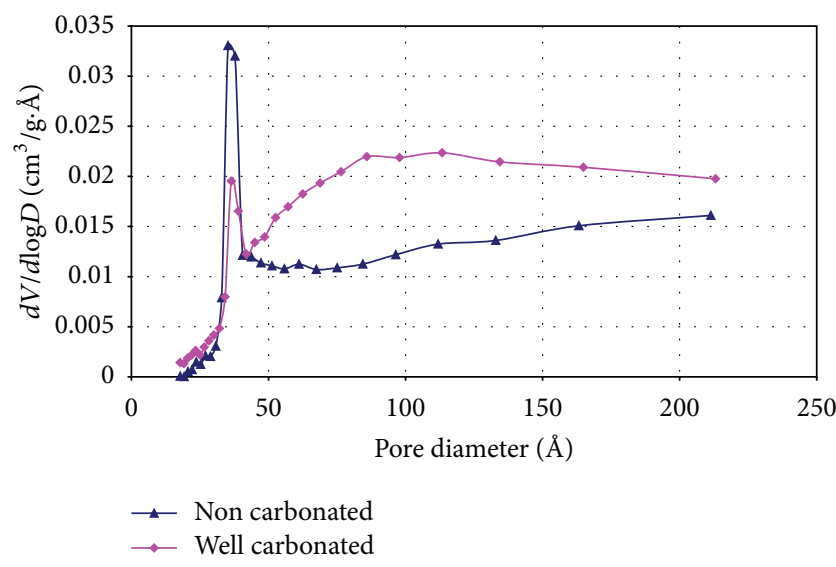

Figure 2: Pore size distribution determined from nitrogen desorption branch of the powder sample.

2.7. Longitudinal and Transverse Ultrasonic Velocities. The ultrasonic setup is composed of a pulse generator and receiver Sofranel model $5800 \mathrm{PR}$, two piezoelectric transducers of longitudinal waves and two piezoelectric transducers of transverse waves, a computer for data acquisition and data processing with a card oscilloscope/digitizer of $20 \mathrm{MHz}$ sampling frequency, and a program of acquisition and signal processing developed under LabView environment.

\section{Results and Discussion}

\subsection{Microstructural Changes Caused by Carbonation}

3.1.1. Nitrogen Adsorption Desorption Isotherms. In Figure 1, we present the nitrogen adsorption isotherms for the two types of samples (well carbonated and noncarbonated). When comparing the isotherms of the well-carbonated sample with those of the noncarbonated sample, we observe that nitrogen adsorption on the carbonated sample is more significant.

Regarding the pore distribution curves (Figure 2), we observe that the carbonation results in a decrease in the micropore volume and an increase in the mesopore volume.

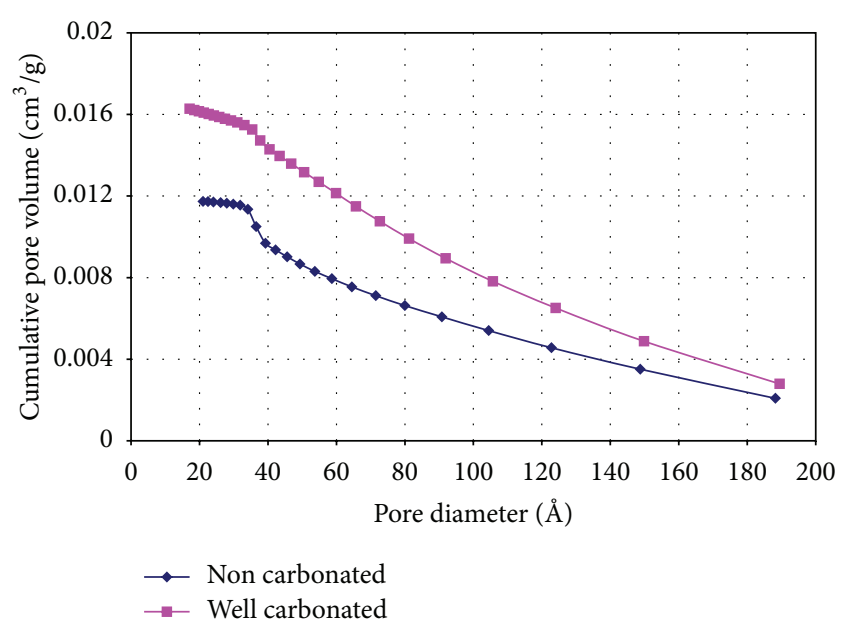

FIGURE 3: Cumulative pore volume determined by nitrogen adsorption.

TABLE 1: Specific surface area of noncarbonated and well-carbonated mortars.

\begin{tabular}{lc}
\hline & $\mathrm{BET}_{\text {nitrogen }}\left(\mathrm{m}^{2} / \mathrm{g}\right)$ \\
\hline Noncarbonated & $5.1 \pm 0.8$ \\
Wellcarbonated & $7.7 \pm 0.7$ \\
\hline
\end{tabular}

TABLE 2: Water-accessible porosity of noncarbonated and wellcarbonated mortars.

\begin{tabular}{lc}
\hline & Porosity (\%) \\
\hline Noncarbonated & $19 \pm 0.2$ \\
Wellcarbonated & $16.1 \pm 0.2$ \\
\hline
\end{tabular}

The carbonation of portlandite is manifested by the crystallisation of numerous calcite crystals on the portlandite plates [13]. Thus, it is understandable that the carbonation results in an increase in the specific surface area (Table 1) and a modification of the pore network.

While the decrease in volume of micropores is attributed to the formation of $\mathrm{CaCO}_{3}$ which clogs the pores, causes of the increase in the volume of mesopores are still discussed. According to Eitel [14], the increase in mesopore volume is caused by the porous structure of the silica gels that are formed during the carbonation. Swenson and Sereda [15] reported that the increase in mesopores is caused by cracks in the $\mathrm{CaCO}_{3}$ gangue that surrounds the portlandite crystals. Other authors have attributed the increase in mesopores to carbonation shrinkage [16].

3.1.2. Total Porosity. We present in Table 2 the porosity accessible to water determined by the classical method using hydrostatic weighing [17]. The results reveal a clear decrease in the total porosity. Similar results have already been reported in the literature $[2,3]$. This result is therefore opposite in comparison with the cumulative pore volume obtained by the nitrogen adsorption (Figure 3). Both techniques seem to cover different porous domains. 
According to Belie et al. [6], the size of nitrogen molecules (radius $0.21 \mathrm{~nm}$ ) does not allow them to access the microporosity, whereas the water molecules (radius $0.1 \mathrm{~nm}$ ) can enter these micropores. Hence, the results of nitrogen adsorption provide information mainly about the mesoporous domain.

In the domain of nano- and micropores, the calcium carbonate formed during carbonation obstructs the pores; by consequence, the water-accessible porosity decreases. Some investigators believe that a major fraction of water molecules taken up by the sample enters spaces between the $\mathrm{C}-\mathrm{S}-\mathrm{H}$ rather than being adsorbed on the existing surface. Hence, the results of porosity accessible to water provide information mainly about the nano- and micropores. The decrease in the volume of micropores inferred from porosity accessible to water was also confirmed in Figure 2, where we presented the pore size distribution calculated from nitrogen adsorption desorption isotherms.

\subsection{Evolution of Macrophysical Properties as a Function of the Duration of Carbonation}

3.2.1. Mass Gain. The carbonation reactions (1), (2) show that a quantity of $\mathrm{CO}_{2}$ was captured to give $\mathrm{CaCO}_{3}$ as a product of carbonation. Also, water released by calcium hydroxide and $\mathrm{C}-\mathrm{S}-\mathrm{H}$ on carbonation may aid the hydration of the unhydrated cement. For this reason, all the mass was measured at dry state to reflect only the gain in mass of the solid phase. An electronic scale was used to measure the mass increase of the specimens due to $\mathrm{CO}_{2}$ uptake. $\mathrm{CO}_{2}$ uptake was determined by the initial mass and the final carbonated mass as shown in the following (3):

$$
\Delta m=\frac{m_{\text {after carbonation }}-m_{\text {initial }}}{m_{\text {initial }}} \cdot 100 \%
$$

The results of the change in mass during carbonation are presented in Figure 4. We observe that the mass increases in a continuous manner. On the other hand, the apparent volume of the specimens remains constant during carbonation. Therefore, we deduce an increase in the density of the mortar after carbonation, which is confirmed by the measures presented in Figure 5. These changes are beneficial and result in improved strength, increased surface hardness, and reduced moisture movement which reduces the potential of efflorescence.

3.2.2. Carbonation Depth. The propagation of $\mathrm{CO}_{2}$ in the cement mortar was revealed by spraying phenolphthalein solution onto the fresh surfaces of samples. We observe in Figure 6 that the carbonation rate in an accelerated carbonation process is much more rapid than that in natural carbonation where it can take several years for a penetration of just several millimetres [1].

Furthermore, the calcite formed during carbonation covers the crystals of portlandite and thus slows the carbonation rate because it becomes more difficult for $\mathrm{CO}_{2}$ to reach the portlandite. This explains why we observe the most important rate of propagation after the first 7 days of carbonation in comparison with the results at 14 and 32 days.

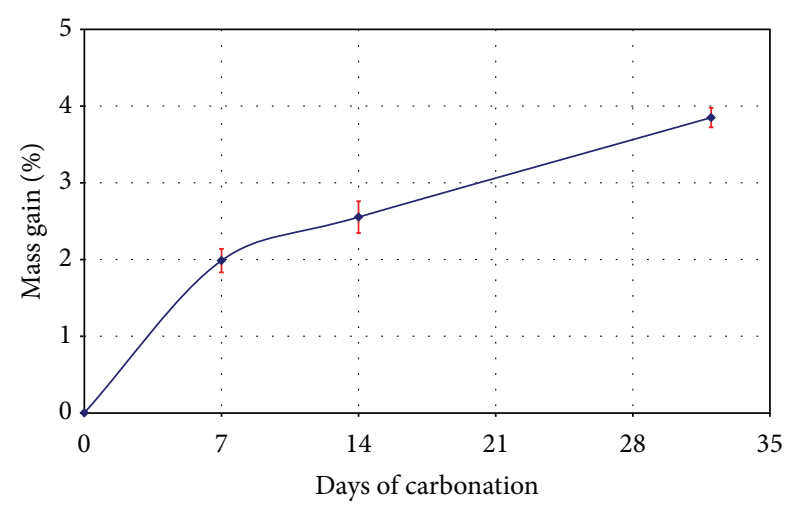

FIgURE 4: Mass gain during carbonation of cement mortar.

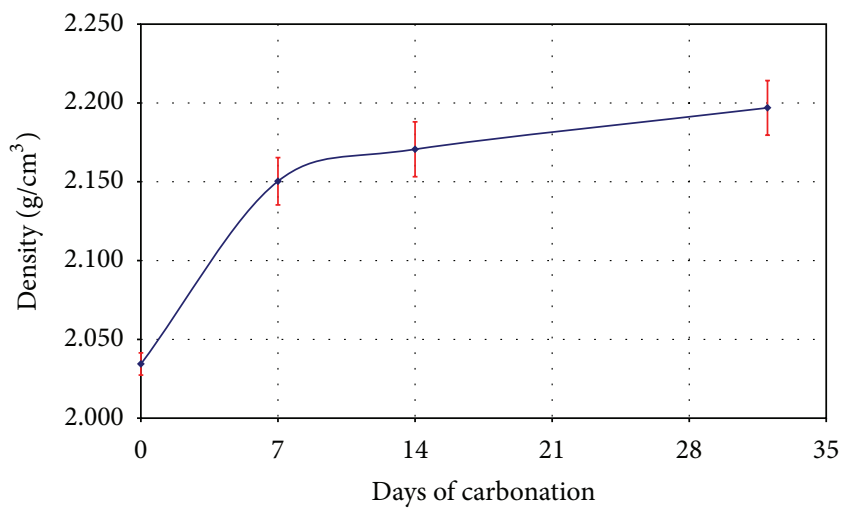

FIGURE 5: Evolution of the density of cement mortar during carbonation.

Although the samples were protected laterally in order to execute an axial carbonation, as a very active gas, the $\mathrm{CO}_{2}$ was still penetrated from the sides as shown in Figure 6. The carbonation depth was thus measured mostly in the middle of the sample in order to eliminate the effects of two-dimension carbonation. Moreover, the bottom of the sample is denser than the top of the sample due to the segregation of aggregates during preparation of cement mortar, which results in a more important carbonation depth at the top than at the bottom of the sample.

In Figure 7, we observe that the carbonation propagation is a linear function with the square root of the duration of carbonation. This result is coherent with the prediction of carbonation depth in the literature: $x=A \cdot \sqrt{t}[1]$, where $A$ is a constant taking into account both the composition of the cement material (water/cement ratio, type of binder,...) and the environmental conditions (relative humidity, temperature, pressure,...).

3.2.3. Porosity Accessible to Water. The results in Figure 8 show that the more the sample is carbonated, the more the porosity accessible to water decreases. When the $\mathrm{CO}_{2}$ reaches deeper in the cement matrix (Figure 7), the quantity of products of carbonation $\left(\mathrm{CaCO}_{3}\right)$ becomes greater and therefore the porosity decreases. By the combination with 


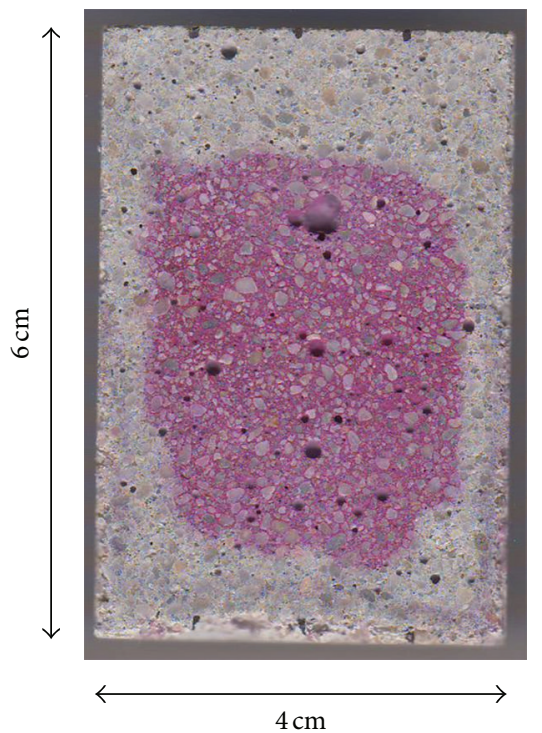

(a)

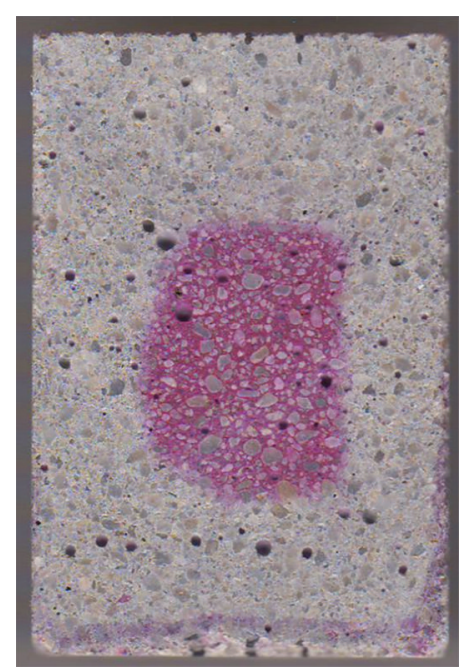

(b)

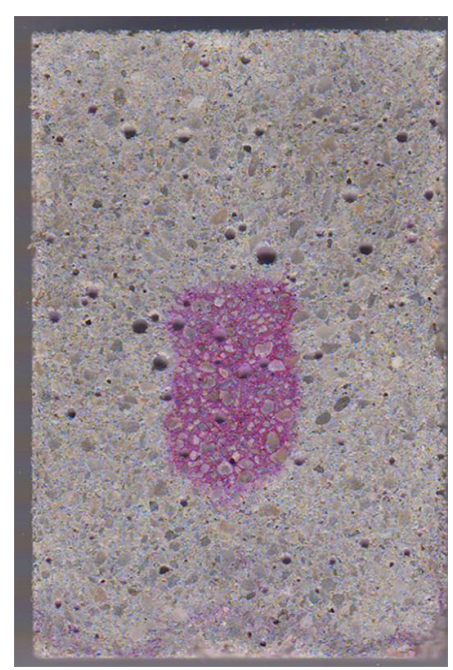

(c)

Figure 6: Propagation of $\mathrm{CO}_{2}$ revealed by phenolphthalein test on samples carbonated for 7 days (a), 14 days (b) and 32 days (c).

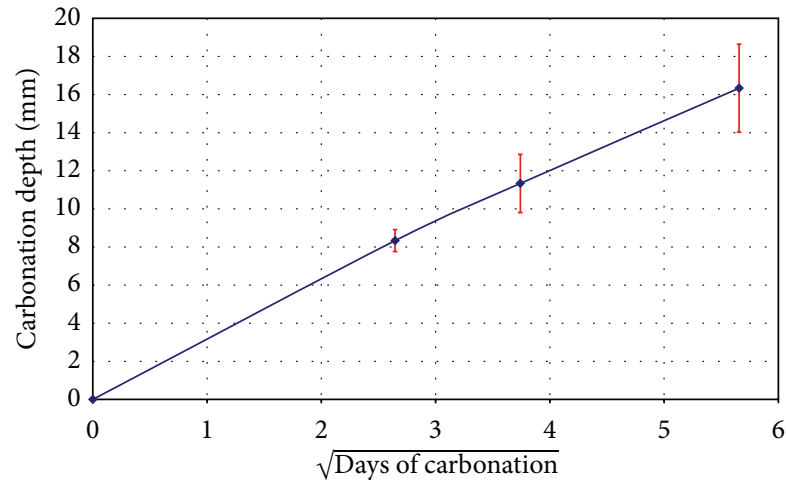

FIGURE 7: Evolution of the carbonation depth during carbonation. the results determined by nitrogen adsorption, we have concluded that the decrease in the total porosity accessible to water is mostly because of the decrease in the volume of micropores. In contrast, the volume of mesopores increases with the carbonation.

3.2.4. Gas Intrinsic Permeability. Measures of gas permeability were performed with the experimental setup as described in Figure 9.

Gas permeability is measured using helium gas according to recommendation standard RILEM TC 116-PCD [18]. Apparent permeability $\left(K_{a}\right)$ is calculated from the HagenPoiseuille equation for laminar flow of a compressible fluid through a porous body under steady state conditions according to

$$
K_{a}=\frac{2 \cdot Q \cdot P_{\mathrm{atm}} \cdot L \cdot \mu}{A\left(P_{i}^{2}-P_{\mathrm{atm}}^{2}\right)}
$$

where $K_{a}$ is apparent permeability to gas of the specimen $\left(\mathrm{m}^{2}\right)$ at fixed pressure (in our case at $1,2,3$, and 5 bars), $L$ is length of the sample (m), $Q$ is measured gas flow $\left(\mathrm{m}^{3} / \mathrm{s}\right), A$ is cross-sectional area $\left(\mathrm{m}^{2}\right), \mu$ is coefficient of viscosity of the gas $(\mathrm{Pa} \cdot \mathrm{s}), P_{i}$ is applied absolute pressure $=$ upstream pressure $(\mathrm{Pa})$, and $P_{\text {atm }}$ is atmospheric pressure $=$ downstream pressure $(\mathrm{Pa})$. The intrinsic coefficient $K$ is obtained by the intersection of the line connecting $K_{a}$ values in function of $1 / P_{i}$ with the coordinate axis.

Figure 10 presents the evolution of the gas intrinsic permeability during carbonation. Contrary to what we expected, an increase in the gas intrinsic permeability was observed. The results seem to be in conflict with the decrease of the porosity. However, the water porosity that decreases after carbonation means that the totality of pores decreases, but

FIGURE 8: Evolution of the porosity accessible to water during carbonation. 


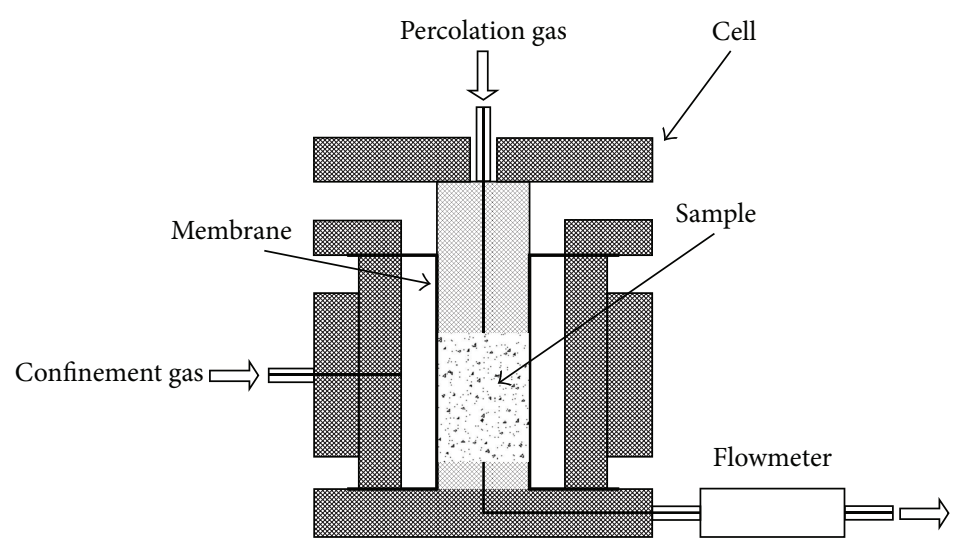

FIGURE 9: Scheme describing the experimental setup of permeability test.

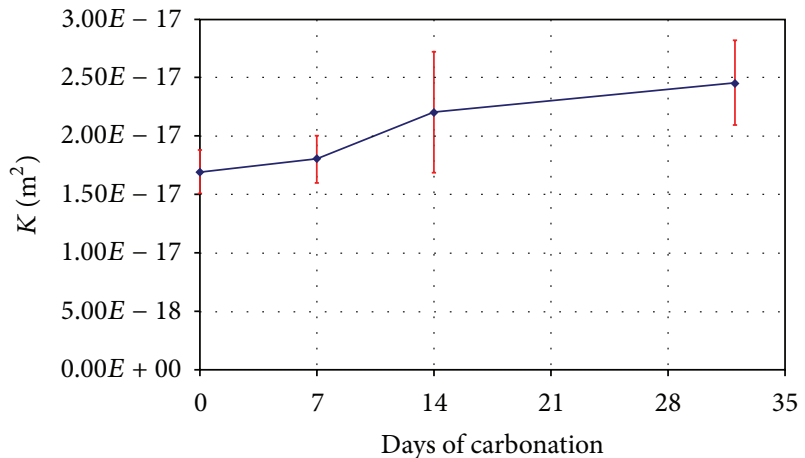

FIGURE 10: Evolution of the intrinsic permeability to helium during carbonation.

TABLE 3: Coefficient of dimension $k$ of mortar during carbonation.

\begin{tabular}{lc}
\hline Days of carbonation & $k$ \\
\hline 0 & $0.0061 \pm 1.44 E-05$ \\
7 & $0.0067 \pm 5.65 E-05$ \\
14 & $0.0067 \pm 1.67 E-04$ \\
32 & $0.0068 \pm 1.65 E-04$ \\
\hline
\end{tabular}

we have no specific information about the meso- and macropores. By the combination with the pore size distribution calculated from nitrogen adsorption, we have concluded that the carbonation resulted in an increase in the volume of mesopores at the expense of the volume of micropores. Therefore, it seems that the evolution of the gas permeability during carbonation is largely influenced by the changes in mesoporous domain: the increase in the volume of mesopores is the cause of the increase in the gas intrinsic permeability. The gas permeability was not influenced by the decrease in the volume of micropores.

3.2.5. Thermal Conductivity and Thermal Diffusivity. Figure 11 presents the thermal conductivity during carbonation. One measure was taken at $65 \%$ of relative humidity, another was taken when the specimens were dried. All measures were performed at $23^{\circ} \mathrm{C}$. We observe an increase

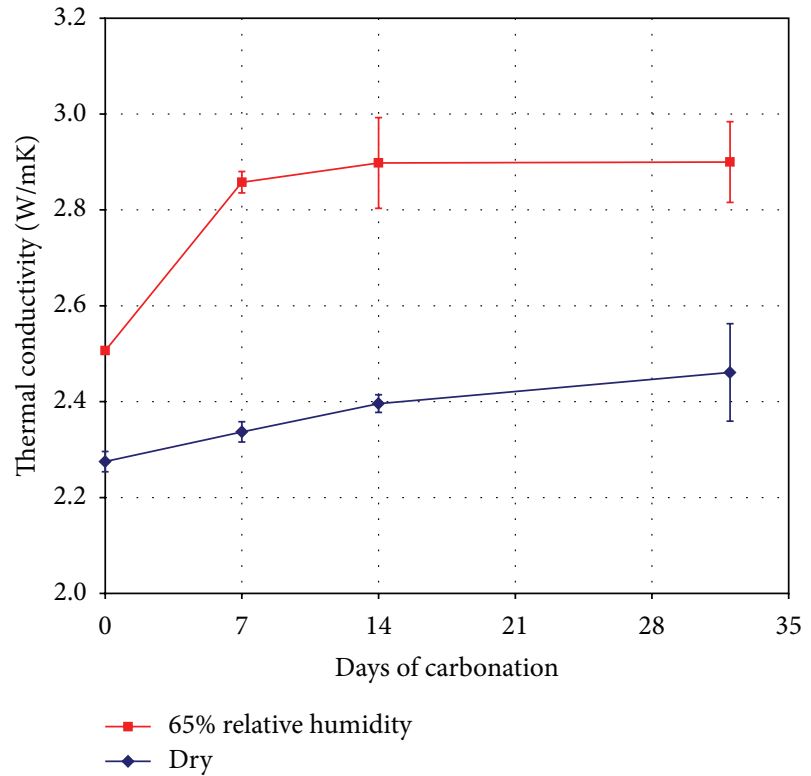

FIGURE 11: The thermal conductivity during carbonation measured at $65 \%$ relative humidity and at dry state.

in the thermal conductivity as a function of the carbonation duration. Due to the low thermal conductivity of the air, the thermal conductivity varies with the density [19]. Hence, the increase in the thermal conductivity during carbonation is coherent with the decrease of the total porosity.

The results show that the thermal conductivity at dry state is smaller than that obtained at $65 \%$ relative humidity. For building materials, it is common to use the following equation to show influence of the relative humidity on the thermal conductivity:

$$
\lambda=k \cdot \lambda_{0} e^{0.08 \mathrm{H}},
$$

where $k$ is a coefficient of dimension, $\lambda_{0}$ is the thermal conductivity of dry material, and $H$ is the relative humidity in percentage. The values of $k$ were calculated and presented in Table 3. We observe that $k$ increases and remains stable after carbonation. $k$ is a characteristic coefficient which is 


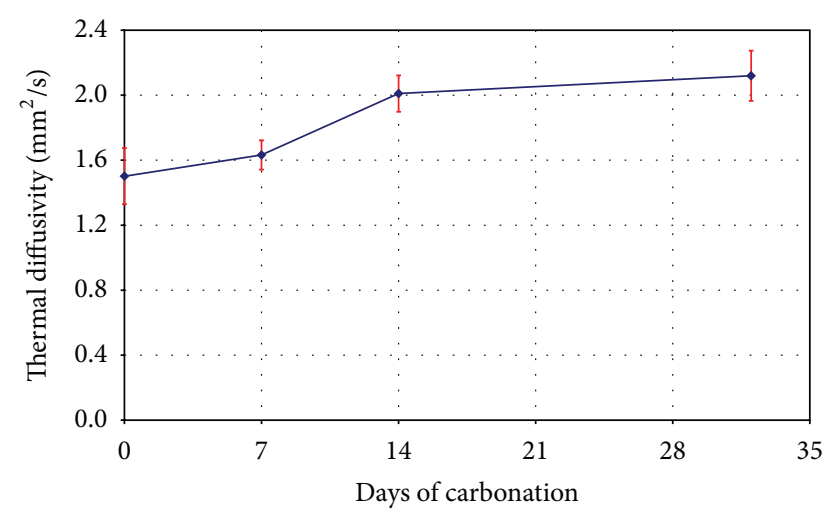

FIGURE 12: Evolution of the thermal diffusivity during carbonation.

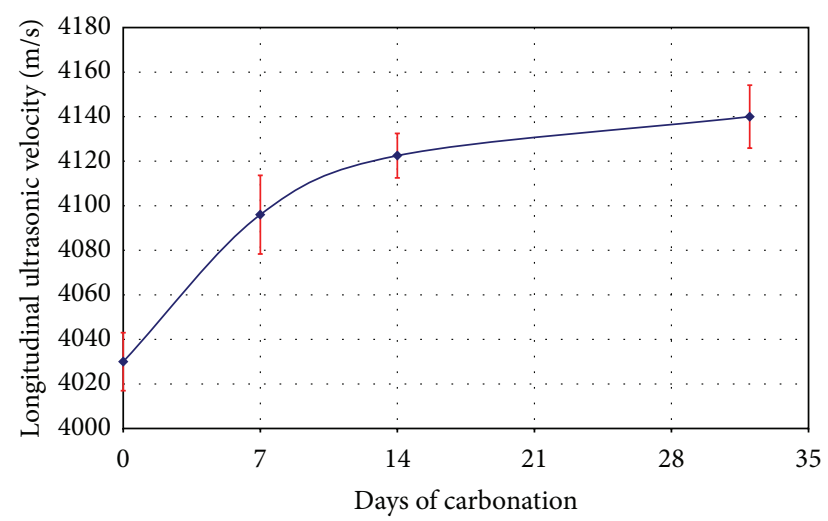

Figure 13: Evolution of the longitudinal ultrasonic velocity $\left(V_{L}\right)$ during carbonation.

unique for each material; it is therefore understandable that $k$ remains stable once the cement mortar is carbonated.

As in the case of the thermal conductivity, we observe also an increase in the thermal diffusivity of dried samples (Figure 12). These results of the thermal conductivity and thermal diffusivity show that the carbonated cement mortar is more sensible to heat transfer than the noncarbonated one.

3.2.6. Ultrasonic Velocities. We present the evolutions of longitudinal and transverse ultrasonic velocity in Figures 13 and 14, respectively. These ultrasonic velocities increase continuously when carbonation occurs. Because the ultrasonic velocity in the air is smaller than that in the dense material, the observations show an increase in the density, which is coherent with the results observed earlier. The characteristics of ultrasonic wave propagation in a material can provide valuable information on material properties, microstructure, and damage state. These methods have many advantages: ease of implementation, ability to work with one side of the material, ability to pass through large thicknesses, and obtaining immediate results of measurements. Furthermore, we can calculate Poisson's ratio and dynamic modulus of elasticity from ultrasonic velocities as follows.

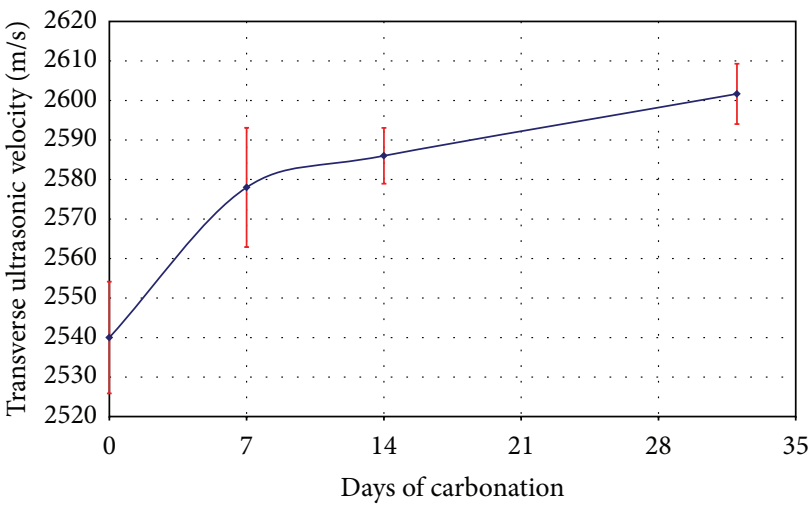

FIGURE 14: Evolution of the transverse ultrasonic velocity $\left(V_{T}\right)$ during carbonation.

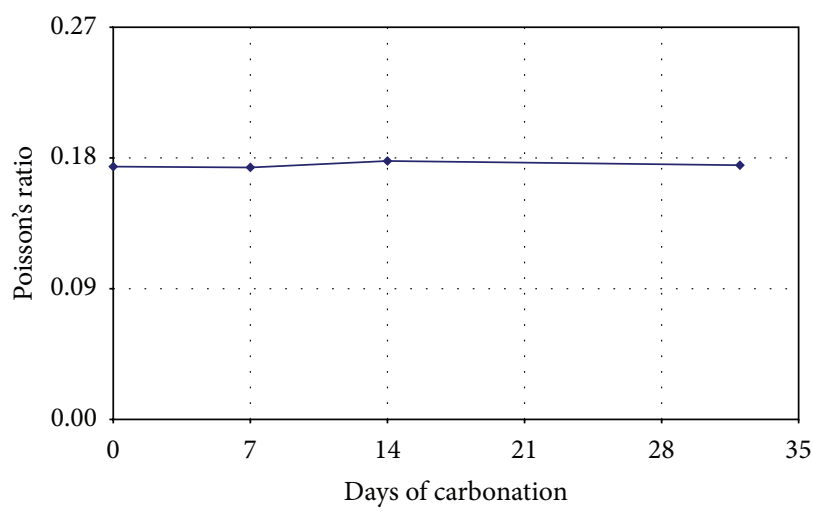

FIgURE 15: Evolution of the Poisson's ratio during carbonation.

Poisson's ratio [20]:

$$
v=\frac{V_{L}^{2}-2 V_{T}^{2}}{2 V_{L}^{2}-2 V_{T}^{2}},
$$

dynamic modulus of elasticity [20]:

$$
E=2 \rho V_{T}^{2}(1+v)
$$

with $\rho$ as the density of the material.

Figure 15 shows that Poisson's ratio remains constant before and after carbonation. In contrast, the dynamic modulus of elasticity increases after carbonation (Figure 16). This results in a stiffer cement mortar. These observations show a positive influence of the carbonation on the cement-based material.

3.2.7. Solid Phase Volume Determined by Helium Pycnometry. Helium pycnometry was used to determine the solid phase volume of samples before and after carbonation. For comparison, the helium pycnometry analysis was also performed on samples which were subjected only to natural carbonation at $20^{\circ} \mathrm{C}$ and $65 \%$ relative humidity without additional $\mathrm{CO}_{2}$. The results are presented in Figure 17 . We can see clearly that the accelerated carbonation resulted in a significant increase in the actual volume in comparison with the natural carbonated 


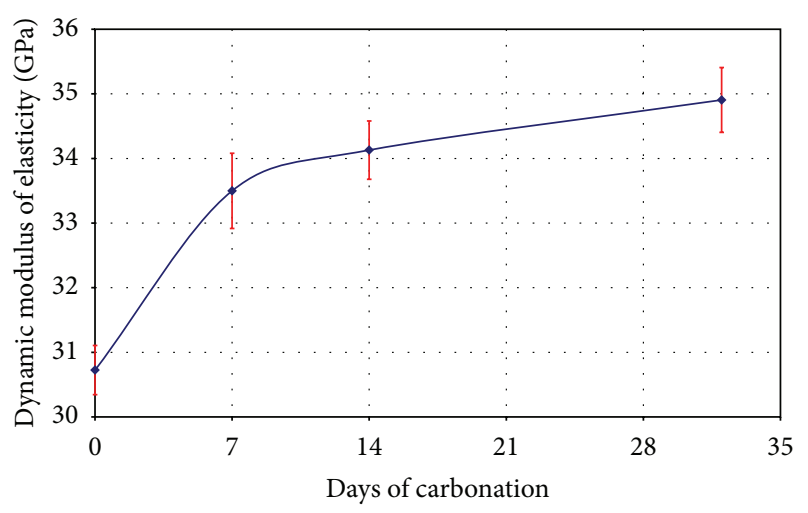

Figure 16: Evolution of the dynamic modulus of elasticity during carbonation.

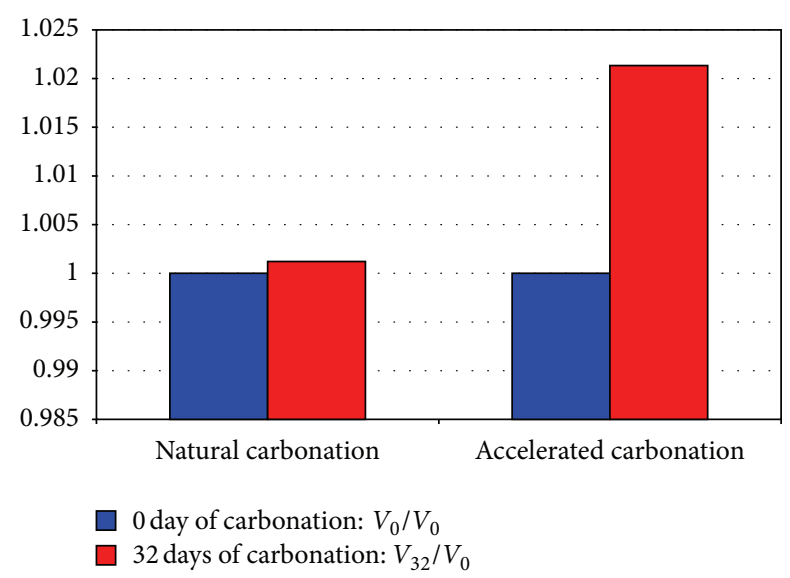

FIGURE 17: Evolution of the solid phase volume during accelerated carbonation and natural carbonation.

sample. The increase in the volume of the solid phase can be explained by the formation of $\mathrm{CaCO}_{3}$ during carbonation, because the carbonation of one mole of portlandite leads to an increase in volume of $4 \mathrm{~cm}^{3}$ [21,22], and the carbonation of one mole of C-S-H leads to an increase in volume of $12 \mathrm{~cm}^{3}$ [23] or $39 \mathrm{~cm}^{3} / \mathrm{mol}$ [2]. Due to differences in the volume, the carbonation product $\left(\mathrm{CaCO}_{3}\right)$ clogs the pores, thereby decreasing the porosity.

\section{Conclusions}

The results of this study indicate that nitrogen and water molecules do not get access into the same porous domains. Investigation using nitrogen adsorption gives information about micro- and especially mesopores, while the one using porosity accessible to water covers all three domains: macro-, meso-, and especially micropores.

Thus, the porosity and specific surface area determined by nitrogen adsorption increase when carbonation occurs. At a given relative pressure, the well-carbonated cement mortar adsorbs more nitrogen than the noncarbonated sample. Furthermore, the adsorption occurs mainly in the mesoporous domain with pore sizes larger than $2 \mathrm{~nm}$.
In contrast, the porosity accessible to water decreases after carbonation. The combination of the two techniques allows to draw a conclusion that, after carbonation, the volume of mesopores increases at the expense of the volume of micropores.

The decrease in the volume of micropores is explained by the formation of $\mathrm{CaCO}_{3}$ during carbonation that obstructs the pores. This results in the increase of the solid phase volume determined by helium pycnometry. Another consequence is the increase of thermal properties, the ultrasonic velocities after carbonation, and the dynamic modulus of elasticity. These observations indicate a positive consequence of carbonation on cement-based materials in terms of strength at the expense of the thermal and sonic insulation.

It appears that the gas intrinsic permeability is mostly influenced by the mesopores. The results show that the increase in volume of mesopores after carbonation might be the cause of the increase in the intrinsic permeability to helium.

\section{References}

[1] Véronique Baroghel Bouny, Conception des bétons pour une durée de vie donnée des ouvrages, Association française de génie civil, 2004.

[2] T. Mickaël, Modelling of Atmospheric Carbonation of Cement Based Materials Considering the Kinetic Effects and Modifications of the Microstructure [Ph.D. thesis], L'école nationale des ponts et chausses, Paris, France, 2005.

[3] V. T. Ngala and C. L. Page, "Effects of carbonation on pore structure and diffusional properties of hydrated cement pastes," Cement and Concrete Research, vol. 27, no. 7, pp. 995-1007, 1997.

[4] W. Jaafar, Influence de la Carbonatation sur la Porosité et la Perméabilité des Bétons, Diplôme d'études Approfondies [M.S. thesis], Laboratoire Central des Ponts et Chaussées, Paris, France, 2003.

[5] H. Naono and M. Hakuman, "Analysis of adsorption isotherms of water vapor for nonporous and porous adsorbents," Journal of Colloid And Interface Science, vol. 145, no. 2, pp. 405-412, 1991.

[6] N. De Belie, J. Kratky, and S. Van Vlierberghe, "Influence of pozzolans and slag on the microstructure of partially carbonated cement paste by means of water vapour and nitrogen sorption experiments and BET calculations," Cement and Concrete Research, vol. 40, no. 12, pp. 1723-1733, 2010.

[7] Q. Zhang, G. Ye, and E. Koenders, "Investigation of the structure of heated Portland cement paste by using various techniques," Construction and Building Materials, vol. 38, pp. 1040-1050, 2013.

[8] S. Brunauer, P. H. Emmett, and E. Teller, "Adsorption of gases in multimolecular layers," Journal of the American Chemical Society, vol. 60, no. 2, pp. 309-319, 1938.

[9] T. A. Bier, J. Kropp, and H. K. Hilsdorf, "Carbonation and realkalinization of concrete and hydrated cement paste," in Durability of Construction Materials, J. C. Maso, Ed., vol. 3, pp. 927-934, Chapman and Hall, London, UK, 1987.

[10] Association française pour la construction et pour la recherche et les essais sur les matériaux et les constructions (AFPCAFREM), "Essai de carbonatation accéléré, mesure de l'épaisseur de béton carbonate," in Durabilité des Bétons, Méthodes Recommandées pour la Mesure des Grandeurs 
Associées à la Durabilité, J. P. Ollivier, Ed., pp. 153-158, Laboratoire des Matériaux et Durabilité des Constructions, Toulouse, France, 1997.

[11] E. P. Barrett, L. G. Joyner, and P. P. Halenda, "The determination of pore volume and area distributions in porous substances. I. Computations from nitrogen isotherms," Journal of the American Chemical Society, vol. 73, no. 1, pp. 373-380, 1951.

[12] J. J. Kollek, "The determination of the permeability of concrete to oxygen by the Cembureau method-a recommendation," Materials and Structures, vol. 22, no. 3, pp. 225-230, 1989.

[13] C. Carde, "La carbonatation," Le Magazine Béton[S], no. 2, pp. 53-54, 2006.

[14] W. Eitel, Silicate Science: Ceramics and Hydraulic Binders, vol. 5, Academic press, New York, NY, USA, 1966.

[15] E. G. Swenson and P. J. Sereda, "Mechanism of the carbonation shrinkage of lime and hydrated cement," Journal of Applied Chemistry, vol. 18, no. 4, pp. 111-117, 1968.

[16] F. Y. Houst and F. H. Wittmann, "Retrait de carbonatation," in Proceedings of the IABSE Symposium, pp. 255-260, Lisbon, Portugal, 1989.

[17] Association française pour la construction et pour la recherche et les essais sur les matériaux et les constructions (AFPCAFREM), "Détermination de la masse volumique apparente et de la porosité accessible à l'eau," in Durabilité des Béton, Méthodes Recommandées pour la Mesure des Grandeurs Associées à la Durabilité, J. P. Ollivier, Ed., pp. 121-124, Laboratoires des Matériaux et Durabilité des Constructions, Toulouse, France, 1997.

[18] RILEM TC 116-PCD, "Permeability of concrete as a criterion of its durability," Material Structure, vol. 32, pp. 174-1179, 1999.

[19] A. M. Neville, Properties of Concrete, Longman Scientific and Technical, London, UK, 1990.

[20] L. Qixian and J. H. Bungey, "Using compression wave ultrasonic transducers to measure the velocity of surface waves and hence determine dynamic modulus of elasticity for concrete," Construction and Building Materials, vol. 10, no. 4, pp. 237-242, 1996.

[21] F. Y. Houst and F. H. Wittmann, "Retrait de carbonatation," in Proceedings of the IABSE Symposium, pp. 255-260, Lisbon, Portugal, 1989.

[22] V. G. Papadakis, C. G. Vayenas, and M. N. Fardis, "Reaction engineering approach to the problem of concrete carbonation," AIChE Journal, vol. 35, no. 10, pp. 1639-1650, 1989.

[23] V. G. Papadakis, C. G. Vayenas, and M. N. Fardis, "Fundamental modeling and experimental investigation of concrete carbonation," ACI Materials Journal, vol. 88, no. 4, pp. 363-373, 1991. 

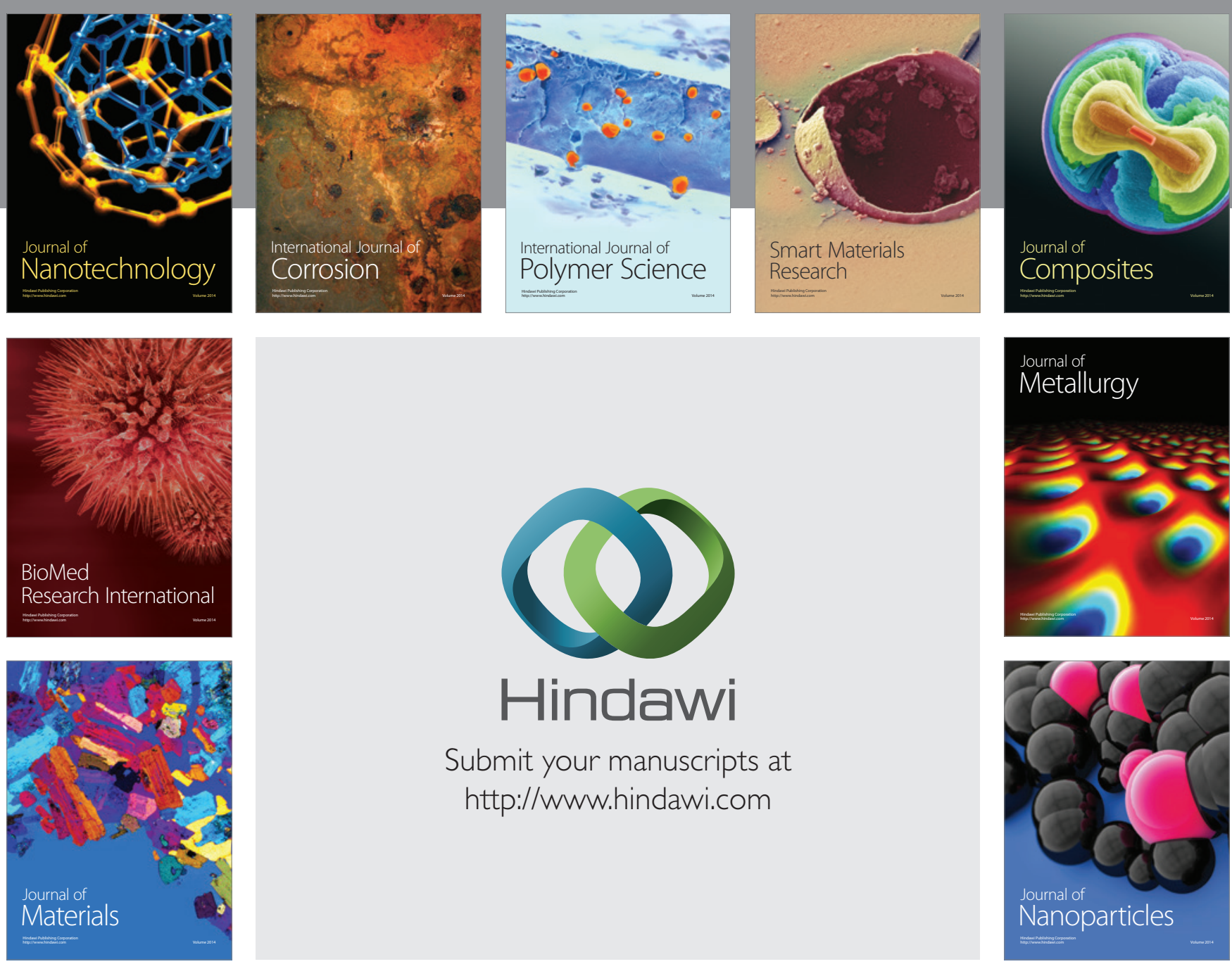

Submit your manuscripts at http://www.hindawi.com
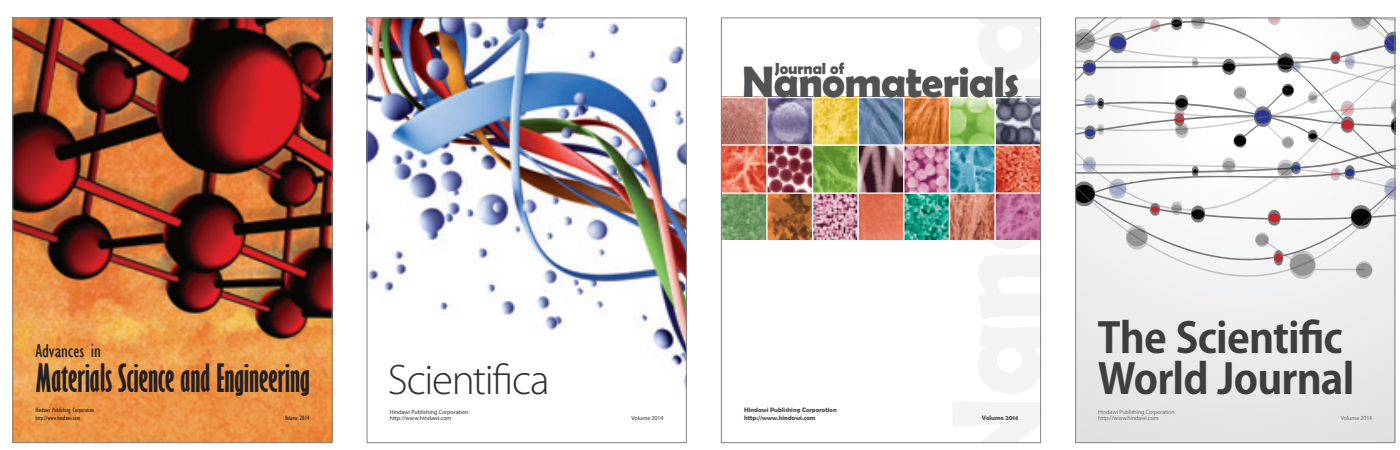

\section{The Scientific World Journal}
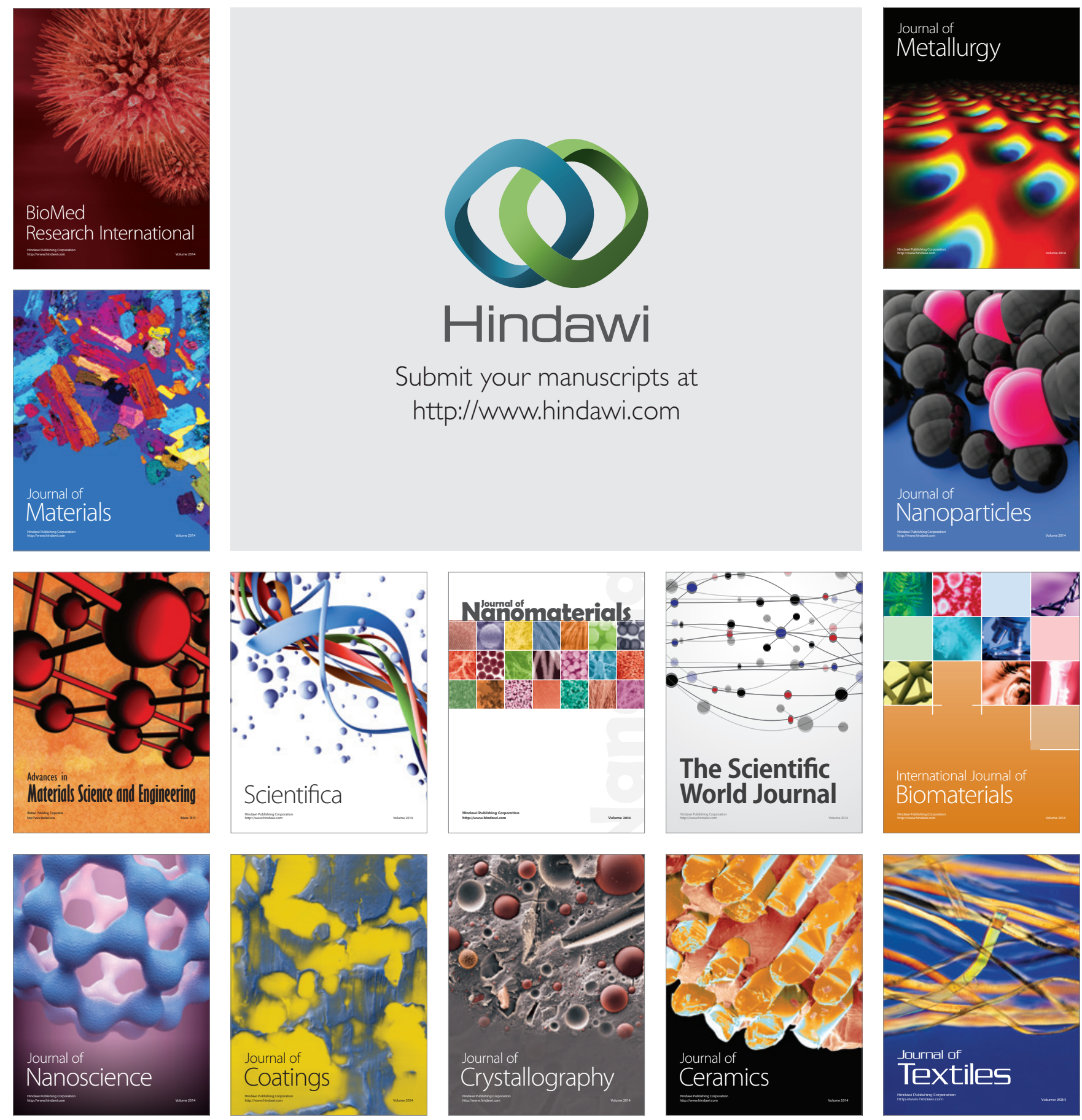